\title{
LAYERS OF OPEN NUCLEUS BREEDING SCHEME IN RELATION TO THE GENETIC IMPROVEMENT OF WEANING WEIGHT IN BARKI SHEEP: A SIMULATION STUDY
}

\author{
Salwa I. El-Wakil \\ Animal and Poultry Breeding \\ Email:salwa_elwakil@yahoo.com \\ Department, Desert Research Centre, El-Matareya, Cairo, Egypt,
}

SUMMARY

The present study investigated the expected genetic gain of weaning weight by changing the stratification of the open nucleus breeding scheme from two tires system (ON2) to three tires one (ON3). The original body weight data were collected from the Barki sheep flock of the Desert Research Centre from 1963 to 2005 with a total number of 1046 animals (542 females and 504 males) progenies of 163 sires and 557 dams. The simulated sets of data were generated from the original data and designed to construct ON3 system consisted of a nucleus flock attached with five multiplier flocks and each of them linked to one commercial flock, whereas ON2 system was constructed by simulating a nucleus flock associated with five commercial flocks. The open nucleus breeding scheme was also simulated to allow for the exchange of superior sires among tires in both directions. Three generations of progenies were obtained by selection of sires and dams for the next generations. The annual genetic gain as a response to selection for weaning weight was also calculated.

Results indicated that breeding values of sires, dams and offspring as well as average weaning weight tended to increase in ON3 and ON2 systems as generations advanced from the first (G1) to the third generation (G3) in nucleus, multiplier and commercial flocks. In both ON2 and ON3 systems, there was a consistent trend for the annual genetic gain of average weaning weight to be the highest in G2 and decreased in G3. Selection for weaning weight for three generations in ON3 system increased average weaning weight from $18.91 \mathrm{~kg}$ to $28.67 \mathrm{~kg}$ (by $51.6 \%$ ) in the nucleus flock, from $17.85 \mathrm{~kg}$ to $26.38 \mathrm{~kg}$ (by $47.8 \%$ ) in multiplier flocks and from $16.33 \mathrm{~kg}$ to $23.17 \mathrm{~kg}$ (by 41.9\%) in commercial flocks. The corresponding values for ON2 were from $19.02 \mathrm{~kg}$ to $28.35 \mathrm{~kg}$ (by 49.1\%) in the nucleus flock and from $16.33 \mathrm{~kg}$ to $25.17 \mathrm{~kg}$ (by $54.1 \%$ ) in commercial flocks. These results clearly indicate that the increase in the annual genetic gain of weaning weight happened in the commercial flocks of ON2 system was much higher (54.1\% vs 41.9\%) than that occurred in the commercial flocks of ON3 system. Moreover, the annual genetic gain for average weaning weight obtained in the commercial flocks of $G 2$ in the ON2 system was three times as much as that occurred in ON3 one (31.7\% and $10.2 \%$, respectively). The respective values in G3 were found to be $28.8 \%$ and $17.1 \%$ for ON3 and ON2, respectively. It is quite clear that the improvement of weaning weight not only was increased in the commercial flocks when the two tires system was applied but also reached faster in the second generation while it delayed to the third generation in case of the three tires system. There is certainly a considerable increase in the genetic response for both ON2 and ON3 systems, however, the practical importance of higher and faster genetic gain, low cost, simplicity and ease of operation might lead to recommending the ON2 system for genetic improvement of weaning weight in Barki sheep.

Keywords: Open nucleus breeding scheme, genetic improvement, weaning weight, Barki sheep

\section{INTRODUCTION}

Barki sheep is dominated in the north western coast (NWC) of Egypt and subjected to harsh climatic conditions and prolonged feed shortage particularly in dry summer season. Genetic improvement of Barki sheep in the NWC is often constrained by small flock size, poor animal identification, inadequate animal performance and pedigree recording, and organizational shortcomings. Under these conditions nucleus breeding schemes can offer practical and cost effective solutions for genetic improvement of small ruminants in developing countries (Jasiorowski, 1990; Gandini et al., 2014). Such breeding scheme is also used when a set of outstanding sires are not available, and there is need to produce better sires for breeding purposes. Applying this system for indigenous breeds can make a significant contribution to the conservation and upgrading of local genetic resources. The scheme may operate as a two or three strata system, and there may be several flocks in each stratum. The breeding program with three-tier scheme includes nucleus, multipliers and commercial flocks. Generally, the nucleus and multiplier flocks generate sires for distribution to commercial flocks. However, the two-tire system is concerned with only one tire to produce superior sires, the nucleus, to be distributed to the second tire, commercial flocks. The systems differed according to the movement of genetic superiority; they are either closed or open. The closed breeding system has no introduction of genetic material from an outside source, whereas, the open breeding system is characterized by a free exchange of sires between nucleus, multipliers and commercial 
flocks (Jackson and Turner, 1972; James, 1977 and Van derWerf, 2000).

Execution of the open nucleus breeding scheme is a long term in nature and costly to implement. Records obtained from Barki sheep flock of the Desert Research Centre while extended for more than forty years, they are insufficient to satisfy the requirement of constructing the nucleus breeding scheme. Results obtained from the original data indicated that selection based on weaning weight might be more effective, compared with birth and yearling weights, hence weaning weight would be the selection objective for the proposed nucleus breeding scheme (El-Wakil et al., 2009).Thus, the present work used the simulation technique to supply larger set of data in order to investigate various alternatives to adopt nucleus breeding scheme, more specifically, to evaluate the expected genetic gain of weaning weight by changing the stratification of the scheme from two tires system to three tires one. That is probably assisting the decision maker in preparing appropriate strategy to genetically improve meat production in Barki sheep.

\section{MATERIALS AND METHODS}

\section{Source of Data:}

The original body weight data used in the present study were collected from the Barki sheep flock raised at Ras ElHekma (RHRS), from 1963 to 1972, and Maryout Research Stations (MRS), from 1973 to 2005. Both RHRS and MRS belong to the Desert Research Centre and located at the north-western coast of Egypt (NWC); RHRS at 250 kilometers west of Alexandria while MRS at 35 kilometers west of Alexandria. In 1972, the sheep flock at RHRS moved to MRS. Flock management was almost the same in RHRS and MRS (El-Wakil et al., 2009). Body weight was recorded from birth till the animal was removed from the flock. Adjustments for individual body weights to different exact ages in the original data were carried out by interpolation between the data of two successive ages; growth during the short intervals was assumed to be linear.

The simulated sets of data were generated from statistical and genetic estimates resulted from the original data with a total number of 1046 animals (542 females and 504 males) progenies of 163 sires and 557 dams. The proposed scheme was simulated as closely as possible to the actual production system prevailing in the NWC to allow for lambing once a year when the new born ram lambs would be available for mating at the age of 16 months.

\section{Simulation procedure:}

The present study dealt with simulating an open nucleus breeding scheme with three tires (ON3; nucleus, multiplier and commercial flocks) and two tires (ON2; nucleus and commercial flocks). Populations of Barki sheep with one record of weaning weight for each animal were generated with assumed mean (0) and variance (1) using the Monte Carlo simulation technique of SAS (2004).For the simulated weaning weight data, parametric values were assumed for phenotypic (19.01), additive genetic (7.75) and residual variances (11.2) as well as the heritability (0.41) according to El-Wakil et al. (2009). According to Analla et al. (1995), the expected genetic value of the progeny $\left(\mathrm{g}_{\mathrm{i}}\right)$ is assumed to be equal to the average genetic values of the parents [sire $\left(g_{s}\right)$ and dam $\left.\left(g_{d}\right)\right]$ plus a deviation due to the Mendelian sampling as follows:

$$
g_{i}=0.5\left(g_{s}+g_{d}\right)+X \sqrt{\left(0.5 h^{2} a_{p}^{2}\right)}
$$

Where $\mathrm{g}_{\mathrm{i}}$ is equal to the expected genetic value of an individual $\mathrm{i},\left(\mathrm{g}_{\mathrm{s}}\right)$ and $\left(\mathrm{g}_{\mathrm{d}}\right)$ are the genetic values of the parents (sire and dam, respectively); $\mathrm{X}$ is a random number taken from normal distribution with mean 0 and variance $1 ; h^{2}$ is the heritability, and $\sigma_{p}^{2}$ is the phenotypic variance.

The genetic values for the first simulated population (producer flock) were taken randomly from a normal distribution with mean zero and variance $\sigma_{g}^{2}=h^{2} \sigma_{p}^{2}$ where $\sigma_{g}^{2}$ is the genetic variance and $\sigma_{p}^{2}$ is the phenotypic one. These producer populations were further analyzed using multiple trait animal model (MTDFREML) proposed by Boldman et al. (1995) for the fixed (year of birth, 10 levels) and random effects (animal, sire and dam) in order to estimate the heritabilities of weaning weight as well as breeding values for sires, dams and their offspring.

The improvement of nucleus, multiplier and commercial flocks occurred as a result of selecting rams and ewes and promoting them according to their breeding values for three successive generations. Improved animals produced from the nucleus flock were propagated by multiplier flocks and hence disseminated to commercial flocks. The multiplier flock is usually regarded to be better than average commercial flocks. Selection is practiced mainly in rams while little selection of dams was performed just to maintain the fixed number of nucleus, multiplier and commercial flocks. The open nucleus breeding scheme allows for the exchange of superior sires between nucleus, multiplier and commercial flocks in both directions. The following flow charts (Figs. 1 and 2) showed the process of simulating the open nucleus breeding scheme with three tires (ON3) and two tires (ON2). The same procedures were repeated for the three generations. The procedure implemented for the ON3 was similarly applied for the ON2 while ignoring the multiplier flocks. The annual genetic gain as a response to selection for weaning weight is calculated as a percentage of an increase in average weaning weight from a given generation to that of the following one. 
Simulation was done to construct open nucleus breeding scheme with

Three tires (ON3)

The scheme consisted of nucleus flock attached with five multiplier flocks and each of them linked to one commercial flock
Two tires (ON2)

The scheme consisted of nucleus flock associated with five commercial flocks

Hundred sets of producer flocks were simulated, each of them is composed of 3000 ewe lambs with their dams $(n=3000)$ and sires $(n=100)$ in addition to their weaning weight and year of birth

These sets were analyzed using MTDFREML (Boldman et al., 1995) to estimate the heritabilities of weaning weight as well as breeding values of their sires, dams and offspring

$>$ sets were chosen and assigned as commercial flocks to be linked with the five multiplier flocks. The other chosen producer flocks were used to form the nucleus and multipliers flocks

To form multiplier flocks, the top $30 \%$ of ewes and sires from each producer flock were screened and chosen according to their average weaning weight. So, each multiplier flock consists of 900 ewes and 30 sires

According to the best estimates of heritability,

five sets of data were chosen and allocated as multiplier flocks to be linked with the nucleus flock

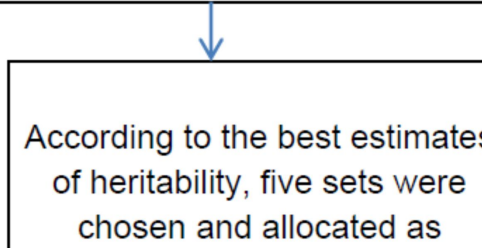
commercial flocks to be linked with the nucleus flock. The other chosen producer flocks were used to form the nucleus flock

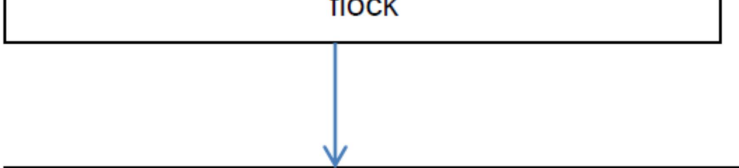

To form nucleus flocks, the top $5 \%$ of ewes and sires from some producer flocks were screened and chosen according to their average weaning weight. Hence, each set composed of 150 ewes and $\mathbf{5}$ sires. Ten sets of data having the best estimates of heritability were chosen to form the nucleus flock of 1500 ewes and 50 sires

Figure (1). The procedure implemented to simulate the formulation of the open nucleus breeding schemes with three tires (ON3) and two tires (ON2). 
In the first mating season, the available sires of the nucleus, multiplier and commercial flocks were mated with the available dams in these flocks in which mating was simulated at a ratio of 30 ewes per ram

Mating seasons were conducted and simulated using the Monte Carlo simulation technique of SAS (2004) to obtain the breeding values of sires, dams and offspring as well as average weaning

In the second mating season, a random mortality rate of $5 \%$ for the least weaning weight
progenies was assumed in both male and female progenies in the nucleus, multiplier and
commercial flocks. The remaining offspring were simulated as males or females by assigning a
random number with a sex ratio of $1: 1$ random number with a sex ratio of $1: 1$

\section{$\downarrow$}

Female progenies of the first season together with those dams from the previous season were screened according to their breeding values to obtain the best females to be introduced in the second matina season

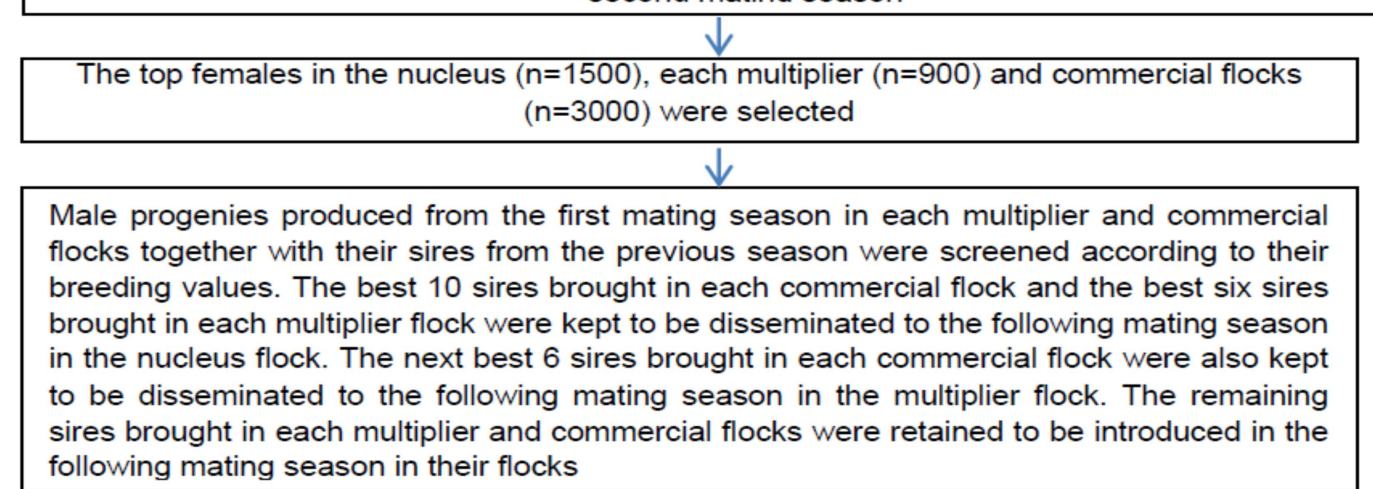
$\downarrow$

Male progenies produced from the second mating season in the nucleus flock and their sires from the previous season together with the best 50 sires received from the commercial flocks and best 30 sires received from the multiplier flocks were screened according to their breeding values. The best 50 sires were maintained to be introduced to the following mating season in the nucleus flock, whereas the next best 30 sires were disseminated to the multiplier flocks (i.e., six sires in each one) and the following best 50 sires were disseminated to the commercial flocks (i.e., ten sires in each one)

\section{$\downarrow$}

The next best sires previously retained in each multiplier flock together with those six sires received from the nucleus flock and those six sires received from the commercial flock were screened according to their breeding values to obtain the best 30 sires to be used in the following mating season in the multiplier flock, the next best 30 sires would be disseminated to the commercial flocks (six sires in each one)

\section{$\downarrow$}

The next best sires previously retained in each commercial flock together with those ten sires received from the nucleus flock and those six sires received from multiplier flocks were screened according to their breeding values to obtain the best 100 sires to be used in the following mating season in the commercial flock

Figure (2). The procedure implemented to simulated producing generations of animals in open nucleus breeding schemes with three tires (ON3) and two tires (ON2).

\section{RESULTS AND DISCUSSION}

Tables (1 and 2) show results of breeding values of sires, dams and offspring as well as average weaning weight obtained from an open nucleus breeding schemes with two tires (ON2) and three tires (ON3) from the first (G1) to the third generation (G3). The tabulated results indicate consistent trends in both systems. Throughout the three generations of selection for weaning weight, results of breeding values of sires, dams and offspring were demonstrated and reflected in the average weaning weight. 
Table 1. The overall average weaning weight (Av. WW) and its breeding values (BV) for sires, dams and offspring in the open nucleus breeding scheme of three tires (nucleus, multiplier and commercial flocks) in three generations (G1 to G3)

\begin{tabular}{|c|c|c|c|c|}
\hline & & G1 & G2 & G3 \\
\hline \multirow[t]{4}{*}{ Nucleus flock } & Sire BV & 4.97 & 14.39 & 18.40 \\
\hline & Dam BV & 0.02 & 1.53 & 5.48 \\
\hline & Offspring BV & 2.60 & 8.05 & 11.86 \\
\hline & Av. WW & 18.91 & 24.36 & 28.67 \\
\hline \multicolumn{5}{|l|}{ Multiplier flocks } \\
\hline \multirow[t]{4}{*}{ M1 } & Sire BV & 2.83 & 10.82 & 15.37 \\
\hline & Dam BV & 0.06 & 1.60 & 4.55 \\
\hline & Offspring BV & 1.63 & 6.16 & 9.96 \\
\hline & Av. WW & 17.94 & 22.47 & 26.27 \\
\hline \multirow[t]{4}{*}{ M2 } & Sire BV & 3.00 & 10.90 & 15.15 \\
\hline & Dam BV & 0.08 & 1.80 & 4.86 \\
\hline & Offspring BV & 1.56 & 6.37 & 10.01 \\
\hline & Av. WW & 17.87 & 22.68 & 26.32 \\
\hline \multirow[t]{4}{*}{ M3 } & Sire BV & 2.92 & 10.98 & 15.46 \\
\hline & Dam BV & 0.05 & 1.66 & 4.69 \\
\hline & Offspring BV & 1.39 & 6.31 & 9.10 \\
\hline & Av. WW & 17.70 & 22.62 & 26.31 \\
\hline \multirow[t]{4}{*}{ M4 } & Sire BV & 2.89 & 11.08 & 15.47 \\
\hline & Dam BV & 0.04 & 1.63 & 4.80 \\
\hline & Offspring BV & 1.53 & 6.56 & 10.10 \\
\hline & Av. WW & 17.84 & 22.87 & 26.41 \\
\hline \multirow[t]{4}{*}{ M5 } & Sire BV & 2.96 & 10.84 & 15.32 \\
\hline & Dam BV & 0.04 & 1.57 & 4.57 \\
\hline & Offspring BV & 1.61 & 6.08 & 10.26 \\
\hline & Av. WW & 17.92 & 22.39 & 26.57 \\
\hline \multirow[t]{4}{*}{ Av. Multiplier flocks } & Sire BV & 2.92 & 10.92 & 15.35 \\
\hline & Dam BV & 0.05 & 1.65 & 4.69 \\
\hline & Offspring BV & 1.54 & 6.30 & 9.89 \\
\hline & Av. WW & 17.85 & 22.61 & 26.38 \\
\hline \multicolumn{5}{|l|}{ Commercial flocks } \\
\hline \multirow[t]{4}{*}{$\mathrm{C} 1$} & Sire BV & 0.00 & 3.43 & 11.57 \\
\hline & Dam BV & 0.00 & 0.00 & 2.04 \\
\hline & Offspring BV & 0.06 & 1.59 & 6.81 \\
\hline & Av. WW & 16.37 & 17.90 & 23.12 \\
\hline \multirow[t]{4}{*}{$\mathrm{C} 2$} & Sire BV & 0.00 & 3.46 & 11.97 \\
\hline & Dam BV & 0.00 & 0.00 & 2.03 \\
\hline & Offspring BV & 0.08 & 1.75 & 6.89 \\
\hline & Av. WW & 16.39 & 18.06 & 23.20 \\
\hline \multirow[t]{4}{*}{ C3 } & Sire BV & 0.00 & 3.42 & 11.91 \\
\hline & Dam BV & 0.00 & 0.00 & 2.15 \\
\hline & Offspring BV & 0.01 & 1.64 & 6.97 \\
\hline & Av. WW & 16.30 & 17.95 & 23.28 \\
\hline \multirow[t]{4}{*}{$\mathrm{C4}$} & Sire BV & 0.00 & 3.43 & 11.59 \\
\hline & Dam BV & 0.00 & 0.00 & 1.96 \\
\hline & Offspring BV & 0.04 & 1.62 & 6.77 \\
\hline & Av. WW & 16.35 & 17.93 & 23.08 \\
\hline \multirow[t]{4}{*}{ C5 } & Sire BV & 0.00 & 3.40 & 11.65 \\
\hline & Dam BV & 0.00 & 0.00 & 2.02 \\
\hline & Offspring BV & 0.07 & 1.80 & 6.84 \\
\hline & Av. WW & 16.24 & 18.11 & 23.15 \\
\hline \multirow[t]{4}{*}{ Av. Commercial flocks } & Sire BV & 00.00 & 3.43 & 11.74 \\
\hline & Dam BV & 00.00 & 00.00 & 2.04 \\
\hline & Offspring BV & 0.05 & 1.68 & 6.86 \\
\hline & Av. WW & 16.33 & 17.99 & 23.17 \\
\hline
\end{tabular}


Table 2. The overall average weaning weight (Av. WW) and its breeding values (BV) for sires, dams and offspring in the open nucleus breeding scheme of two tires (nucleus and commercial flocks) in three generations (G1 to G3).

\begin{tabular}{|c|c|c|c|c|}
\hline & & G1 & G2 & G3 \\
\hline \multirow[t]{5}{*}{ Nucleus flock } & Sire BV & 4.95 & 13.61 & 18.51 \\
\hline & Dam BV & 0.02 & 1.84 & 5.52 \\
\hline & Offspring BV & 2.71 & 7.67 & 12.04 \\
\hline & Av. WW & 19.02 & 23.98 & 28.35 \\
\hline & & & $26.1 \%$ & $18.2 \%$ \\
\hline \multicolumn{5}{|l|}{ Commercial flocks } \\
\hline \multirow[t]{4}{*}{ C1 } & Sire BV & 0.00 & 9.05 & 13.70 \\
\hline & Dam BV & 0.00 & 1.78 & 4.52 \\
\hline & Offspring BV & 0.00 & 5.33 & 9.15 \\
\hline & Av. WW & 16.30 & 21.64 & 25.46 \\
\hline \multirow[t]{4}{*}{$\mathrm{C} 2$} & Sire BV & 0.00 & 8.39 & 13.30 \\
\hline & Dam BV & 0.00 & 1.51 & 4.05 \\
\hline & Offspring BV & 0.01 & 4.94 & 8.67 \\
\hline & Av. WW & 16.31 & 21.25 & 24.98 \\
\hline \multirow[t]{4}{*}{$\mathbf{C 3}$} & Sire BV & 0.00 & 8.64 & 13.30 \\
\hline & Dam BV & 0.00 & 1.59 & 4.26 \\
\hline & Offspring BV & 0.04 & 5.20 & 8.92 \\
\hline & Av. WW & 16.35 & 21.51 & 25.23 \\
\hline \multirow[t]{4}{*}{$\mathrm{C4}$} & Sire BV & 0.00 & 8.90 & 13.36 \\
\hline & Dam BV & 0.00 & 1.56 & 4.21 \\
\hline & Offspring BV & 0.02 & 5.13 & 8.70 \\
\hline & Av. WW & 16.33 & 21.44 & 25.00 \\
\hline \multirow[t]{4}{*}{ C5 } & Sire BV & 0.00 & 8.82 & 13.42 \\
\hline & Dam BV & 0.00 & 1.63 & 4.34 \\
\hline & Offspring BV & 0.05 & 5.33 & 8.86 \\
\hline & Av. WW & 16.36 & 21.64 & 25.17 \\
\hline \multirow[t]{5}{*}{ Av. Commercial flocks } & Sire BV & 00.00 & 8.76 & 13.42 \\
\hline & Dam BV & 00.00 & 1.61 & 4.28 \\
\hline & Offspring BV & 0.02 & 5.19 & 8.86 \\
\hline & Av. WW & 16.33 & 21.50 & 25.17 \\
\hline & & & $31.7 \%$ & $17.1 \%$ \\
\hline
\end{tabular}

Breeding values of sires, dams and offspring as well as the average weaning weight tended to increase as generations advanced in ON3 and ON2 systems from G1 to G3 in nucleus, multiplier and commercial flocks (Tables 1 and 2). There is a steady trend for the annual genetic gain of average weaning weight to be the highest in G2 and was decreased in G3 which is probably due to the improvement occurred in average weaning weight as a result of decreasing the gap between improved and unimproved animals in both ON2 and ON3 systems. Similar trend was observed in the Egyptian buffaloes (Abdel-Salam et al., 2010). On the other hand, selection for weaning weight for three generations in ON3 system increased average weaning weight from $18.91 \mathrm{~kg}$ to $28.67 \mathrm{~kg}$ (by $51.6 \%$ ) in the nucleus flock, from $17.85 \mathrm{~kg}$ to $26.38 \mathrm{~kg}$ (by $47.8 \%$ ) in multiplier flocks and from $16.33 \mathrm{~kg}$ to $23.17 \mathrm{~kg}$ (by $41.9 \%$ ) in commercial flocks (Table 1). The corresponding values for ON2 were from $19.02 \mathrm{~kg}$ to $28.35 \mathrm{~kg}$ (by $49.1 \%$ ) in the nucleus flock and from $16.33 \mathrm{~kg}$ to $25.17 \mathrm{~kg}$ (by 54.1\%) in commercial flocks (Table 2). The aforementioned results clearly indicate that the increase in the annual genetic gain of weaning weight happened in the commercial flocks of ON2 system was much higher $(54.1 \%$ vs $41.9 \%)$ than that occurred in the commercial flocks of ON3 system. Moreover, the annual genetic gain for average weaning weight obtained in the commercial flocks of G2 in the ON2 system was three times as much as that occurred in $\mathrm{ON} 3$ one $(31.7 \%$ and $10.2 \%$, respectively). The respective values in G3 were found to be $28.8 \%$ and $17.1 \%$ for ON3 and ON2, respectively (Tables 1 and 2). It is quite clear that the improvement of weaning weight not only increased in the commercial flocks when the two tires system was applied but also reached faster in the second generation whereas it delayed to the third generation in case of three tires system.

It appeared that nucleus flock has almost the same trend in both ON2 and ON3 systems whereas the remarkable difference between $\mathrm{ON} 2$ and $\mathrm{ON} 3$ systems happened in the commercial flocks, as previously mentioned, which is the main target of any breeding program. Multiplier flocks existed only in the ON3which is often operating to increase the number of superior sires produced in the nucleus to transfer genetic progress to commercial flocks. It is probably takes time to disseminate the genetic progress, through multiplier flocks, to commercial flocks of ON3 system compared with the quick genetic response appeared in the commercial flocks 
of ON2 system. Furthermore, cost as well as management and operating multiplier flocks in ON3 have to be considered. On the other hand, ON2 is more commonly adopted because of its simplicity and ease of operation (Van derWerf, 2000). It is emphasized that the success of the breeding programs generally is not only determined by their inherent structure, genetic gain and profitability but also by their compatibility with the farming conditions and the involvement of farmers as well as simplicity and applicability of the system together with those factors to ensure its successful implementation and sustainability (Gicheha et al., 2006; Kosgey et al., 2006).

In the present study, there is certainly a considerable increase in the genetic response for both ON2 and ON3 systems. However, the practical importance of higher and faster genetic gain, low cost, simplicity and ease of operation might lead to recommend the ON2 system for genetic improvement of weaning weight in Barki sheep. Practically, it might be wise to initiate the open nucleus breeding scheme applying the two-tier system to speed the genetic progress in commercial flocks which is the main target. If there is any shortage in the production of improved sires, the stratum of multiplier flocks could be introduced to the system.

\section{REFERENCES}

Abdel-Salam, S. A., Sayed A. I., Manal Elsayed, and S. Abou-Bakr, 2010. Genetic gain in open nucleus breeding scheme to improve milk production in Egyptian Buffalo. Livestock Science, (131)162-167.

Analla, M.; A. Sanchez, A. Munaz and J. M. Serradilla, 1995. Simulation analysis with BLUP methodology of different data structure in goat selection schemes in Spain. Small Ruminant Research, 17:51.

Boldman, K. G., L. A. Kriese, , L. D. Van Vleck and C. P. Van Tassell, 1995. A manual for use of MTDFREML. A set of programs to obtain estimates of variances and covariances. Agricultural Research Service, U. S. Department of Agriculture, Washington.

El-Wakil, Salwa I., Manal ElSayed, A. M. Ahmed, R. R. Sadek and A. A. Nigm, 2009. Genetic and phenotypic parameters of birth, weaning and yearling body weights of Barki sheep raised in the north-western coast of Egypt. Egyptian Journal of Animal Production, 46(1): 43-52.

Gandini, G., M. Del Corvo, F. Biscarini and A. Stella, 2014. Genetic improvement of small ruminant local breeds with nucleus and inbreeding control: A simulation study. Small Ruminant Research, Volume 120 (2-3): 196-203.

Garrick, D. J., H.T. Blair and J. N. Clarke, 2000. Sheep industry structure and genetic improvement. Proceedings of the New Zealand Society of Animal Production, (60): 175-179.

Gicheha, M.G., I.S. Kosgey, B.O. Bebe and A.K. Kahi, 2006. Evaluation of the efficiency of alternative two-tier nucleus breeding systems for meat sheep in Kenya. J. Anim. Breed. Genet., 123 (4), 247-257.

Jackson, N. and H. N. Turner, 1972. Optimal structure for a co-operative nucleus breeding system. Proceeding of the Australian Society of Animal Production, (9): 55-64.

James, J.W., 1977. Open nucleus breeding systems. Animal Production, 24: 287-305.

Jasiorowski, H.A., 1990. Open nucleus breeding schemes-new challenge for the developing countries. In: Animal Science Papers and Reports 6, Polish Academy of Sciences, Institute of Genetics and Animal Breeding, Jastrz c ebiec, Proceedings of the FAO Conference on Open Nucleus Breeding Systems, Białobrzegi, Poland, 11-19 June 1989. Polish Scientific Publishers, Warszawa, pp. 7-12.

Kosgey, I.S., R. L. Baker, H. M. J. Udo, J. A. M. Van Arendonk, 2006. Successes and failures of small ruminant breeding programmes in the tropics: a review. Small Ruminant Research, 61(1): 13-28.

Rae, A. L., 1974. The development of group breeding schemes: some theoretical aspects. Sheep farming Annual, p.121-127.

SAS., 2004. Statistical Analysis System. SAS User's Guide: Statistics. SAS Institute Inc. Editors, Cary, NC.

Van der Werf, J., 2000. Livestock straight breeding system structures for the sustainable intensification of extensive grazing systems. In: Galal, S., Boyazoglu, J., Hammond, K. (Eds.), Proceedings of the Workshop on Developing Breeding Strategies for Lower Input Animal Production Environments, Bella, Italy, 22-25 September 1999, ICAR Technical Series 3, pp. 105-177. 
علاقة طبقات برنامج النواة المفتوحة بالتحسين الوراثى لوزن الفطام فى الأغنام البرقى: دراسة محاكاة

سلوى إبراهيم الوكيل

قسم تربية الحيوان والدواجن ، مركز بحوث الصحراء، المطرية، القاهرة، مصر

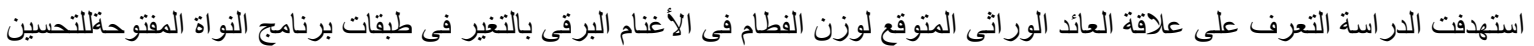

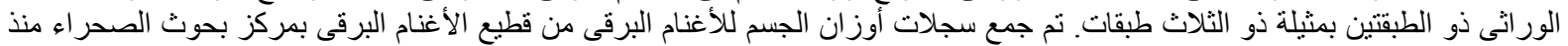

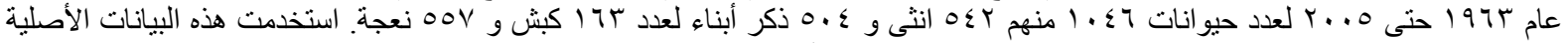

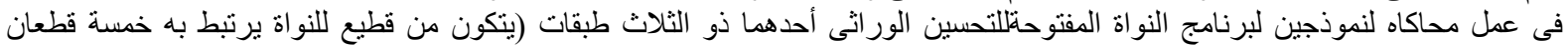

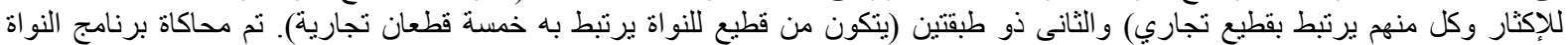

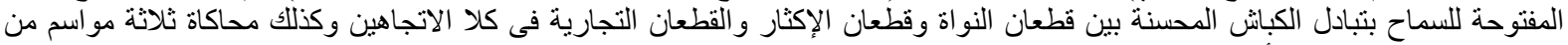

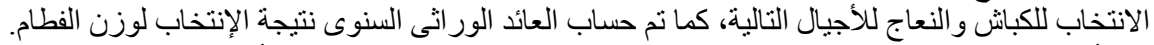

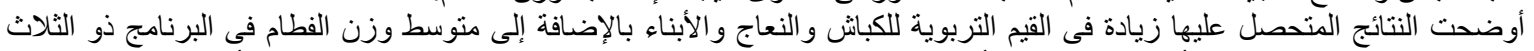

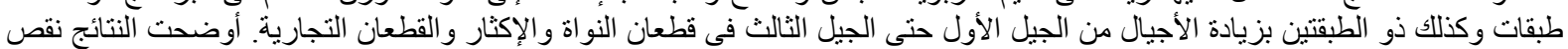

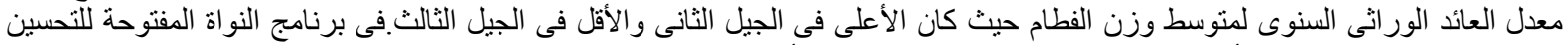

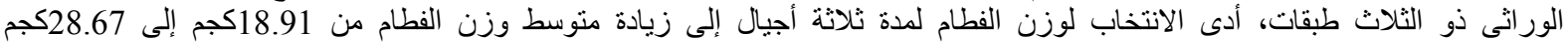

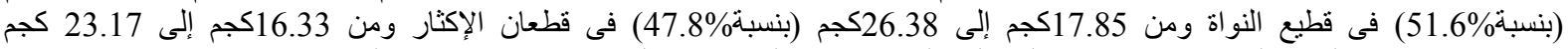

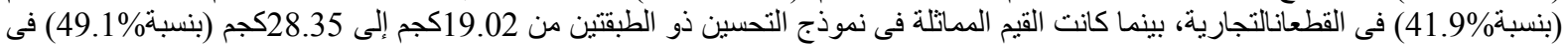

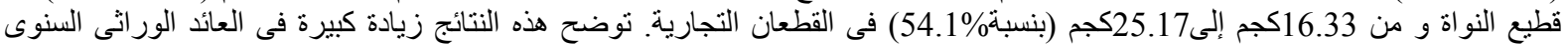

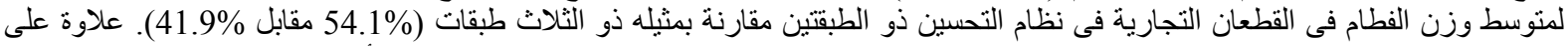

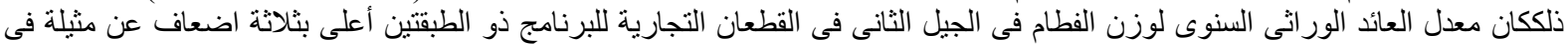

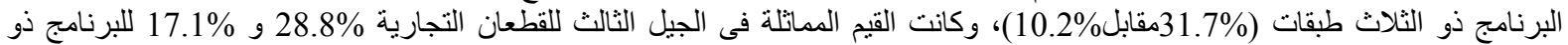

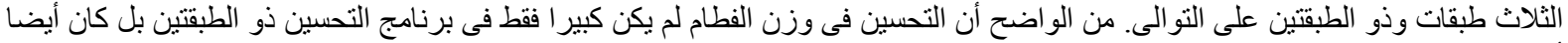

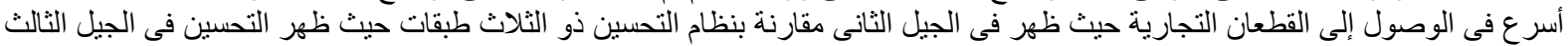

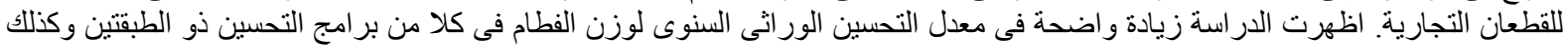

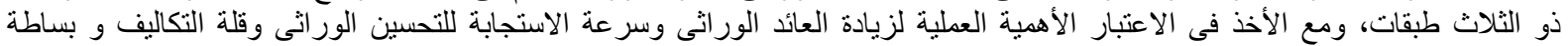

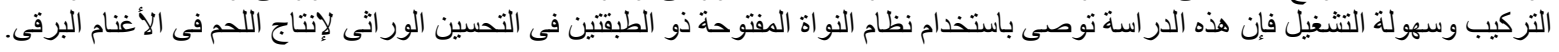

